Instructions for authors, subscriptions and further details:

http://ijep.hipatiapress.com

\title{
Cognitive Abilities of Pre- and Primary School Children with Spina Bifida in Uganda
}

Femke Bannink ${ }^{1}$, Johnny R. J. Fontaine ${ }^{1}$, Richard Idro $^{2}$, Geert van Hove ${ }^{1}$

1) Ghent University, Belgium

2) Makerere University, Uganda

Date of publication: October $24^{\text {th }}, 2016$

Edition period: October 2016 - February 2017

To cite this article: Bannink, F., Fontaine, J. R. J., Idro, R., van Hove, G. (2016). Cognitive Abilities of Pre- and Primary School Children with Spina Bifida in Uganda. International Journal of Educational Psychology, 5(3), 249-280. doi: 10.17583/ijep.2016.2075

To link this article: http://dx.doi.org/10.17583/ijep.2016.2075

\section{PLEASE SCROLL DOWN FOR ARTICLE}

The terms and conditions of use are related to the Open Journal System and to Creative Commons Attribution License (CC-BY). 


\section{Cognitive Abilities of Pre- and Primary School Children with Spina Bifida in Uganda}

Femke Bannink, Johnny R. J. Fontaine, Geert van Hove Ghent University
Richard Idro Makerere University

\section{Abs tract}

This study investigates cognitive abilities of pre/primary school children without and with spina bifida in Uganda. Qualitative semi structured interviews and quantitative functioning scales measurements were combined and conducted with 133 parents, 133 children with spina bifida, and 35 siblings. ANCOVA was used to test for differences in cognitive scores between children and siblings. Logistic regression analyses were used to study predictive demographic, impairment specific, and environmental factors of cognitive functioning. Children with spina bifida in Uganda had lower cognitive outcomes compared to their siblings. Cognitive outcomes were predicted by age, household income, motor functioning, and schooling. Better motor functioning was predicted by age, the presence of hydrocephalus, and parental support. Continence management was predicted by parental support and household income. Schooling was predicted by age, household income, and motor functioning. Limited access to neurosurgery and rehabilitative care, and schooling had a negative effect on cognitive functioning. Children of parents who have support had better motor functioning, and continence management. A holistic approach for children with spina bifida and their families, including community based rehabilitation; ensuring social support and livelihoods for parents; and access to health and education services can contribute to better cognitive outcomes.

Keywords: Cognitive abilities, motor function, schooling, spina bifida, Africa 


\section{Habilidades Cognitivas de Estudiantes de Educación Infantil y Primaria con Espina Bífida en Uganda}

Femke Bannink, Johnny R. J. Fontaine, Geert van Hove Ghent University

\author{
Richard Idro \\ Makerere University
}

\section{Resumen}

Este estudio investiga las habilidades cognitivas de estudiantes de educación infantil y primaria con y $\sin$ espina bífida en Uganda. Entrevistas cualitativas semiestructuradas y escalas funcionales fueron combinadas y aplicadas a 133 padres, 133 niños con espina bífida y 35 hermanos. Se utilizó ANCOVA para analizar las diferencias en puntuaciones cognitivas entre los niños y sus hermanos. Análisis de regresión logística se utilizaron para estudiar factores predictores de funcionamiento cognitivo, como demográficos, específicos de la discapacidad y ambientales. Los niños con espina bífida en Uganda tuvieron resultados cognitivos más bajos que sus hermanos. Los resultados cognitivos fueron predichos por la edad, la presen cia de hidrocefalia y el apoyo parental. La gestión de la continencia fue predicha por el apoyo parental y los ingresos en el hogar. La escolarización se predijo por la edad, los ingresos en el hogar y el funcionamiento motor. El acceso limitado a la neurocirugía y al cuidado de tipo rehabilitador, y la escolarización tuvieron un efecto negativo sobre el funcionamiento cognitivo. Los niños de padres con apoyo tuvieron mejor funcionamiento motor y gestión de la continencia. Un enfoque holístico para niños con espina bífida y sus familias, incluyendo rehabilitación basada en la comunidad, asegurando apoyo social y la subsistencia para padres, así como el acceso a los servicios de salud y educativos pueden contribuir a mejores resultados cognitivos.

Palabras clave: habilidades cognitivas, función motora, escolarización, espina bífida, África. 
V

ery little is known about the impact of spina bifida on cognitive development among pre- and primary school children in low income countries. In the current study we have investigated differences in cognitive abilities between pre/primary school children without and with spina bifida as well as the factors that best predict cognitive development among children with spina bifida in the Ugandan context.

\section{Spina bifida}

Spina bifida is a congenital disability and neural tube defect in which the spinal cord and vertebrae do not form completely and the neural tube fails to develop normally (Northrup \& Volcik, 2000). In Uganda an estimated 1,400 children are born with spina bifida annually (Warf, Wright, \& Kulkarni, 2011). The majority of these have some degree of paralysis, which affects mobility as well as bowel and bladder control (Abresch et al, 2007; Andren \& Grimby, 2000; Danielsson et al., 2008; Northrup \& Volcik, 2000; Verpoorten \& Buyse, 2008), and 66\% develops hydrocephalus (Warf \& Campbell, 2008). In hydrocephalus the natural circulation of cerebrospinal fluid (CSF) in the brain is obstructed and fluid accumulates. The excess fluid presses on the brain causing damage to the surrounding tissue. In babies and infants where the skull is still soft, the head enlarges (CURE, 2008; IFSBH, 2014). Most children with spina bifida need surgery to close the back to prevent infections; and those with hydrocephalus need endoscopic third ventriculostomy (ETV) or placement of a ventriculo-peritoneal (VP) shunt to drain cerebral spinal fluid and prevent secondary impairments (IFSBH, 2014; Warf, 2005).

\section{Cognitive functioning of children with spina bifida}

Research in high income countries suggests that a broad range of cognitive abilities is affected in children with spina bifida (Dennis \& Barnes, 2010). They are at risk for difficulties in attention (not sustained attention or ADHD) (Fletcher et al 2005; Rose \& Holmbeck, 2007), short-term memory, prospective memory, immediate and delayed episodic memory (Dennis et al, 2007), nonverbal learning disabilities, language comprehension and 


\section{Bannink et al. - Cognitive Abilities}

discourse (Pike et al, 2013), and approximate and standardized arithmetic measures (Raghubar et al., 2015). Children with spina bifida and hydrocephalus have lower cognitive function scores compared to children with spina bifida alone (Iddon et al, 2004).

To our knowledge no studies on cognitive functioning in pre-primary and primary school aged children with spina bifida have taken place in subSaharan Africa. Warf et al (2009) studied neurocognitive outcomes in infants with spina bifida aged 5 to 52 months in Uganda, and found infants not requiring treatment for hydrocephalus had significantly better neurocognitive outcomes compared to those who did require treatment (Warf et al., 2009). The present study focuses on the cognitive impact of spina bifida among pre-school and primary school aged children in Uganda. We compare children with spina bifida with their siblings and we investigate those factors that predict differences in cognitive abilities within the group of children with spina bifida. We investigate the predictive value of demographic factors that have been found to relate to cognitive abilities in general, of characteristics that are typical for children with spina bifida, and of characteristics that are typical to the Ugandan context.

\section{Demographic factors contributing to cognitive functioning}

Demographic variables included in our study were age, gender, socioeconomic status, and geographic location. We expected that cognitive outcomes increase with age and socio-economical status. We did not expect to find gender differences. One of the most basic findings in intelligence research is that cognitive abilities increase with age until late adolescence (Hunt, 2010). Whilst there is no evidence for general differences in cognitive ability for boys and girls, gender differences have been found on specific cognitive outcomes depending on the type of cognitive testing administered. For instance, girls performed better verbally, whilst boys performed better on quantitative reasoning in earlier studies (Halpern, 2011; Strand, Deary, \& Smith, 2006).

Cognitive abilities correlate not very highly, but systematically (about .30) with socio-economic status (SES) (Hunt, 2010). Whilst income on its own does not predict cognitive abilities, parents with higher SES do spend more time with their children in ways that stimulate cognitive functioning 
compared to parents with lower SES (Hunt, 2010). Poverty is a factor contributing to cognitive functioning in children with spina bifida in high income countries (Dennis et al, 2006; Fletcher, Barnes, \& Dennis, 2002). Dennis et al (2006) found socioeconomic status plays an important role in the provision of appropriate remediation for specific cognitive and academic skills. They argue for more studies on how environmental factors such as poverty affect cognitive outcomes which provide approaches to enhance outcomes aside scientific understanding (Dennis et al., 2006). In our study we expect that children from parents with higher SES will have better cognitive outcomes as parents are more likely to provide their children with basic needs and access services.

Differences in cognitive outcomes between urban and rural areas are linked to poverty, schooling, and other environmental factors (Dennis et al, 2006). Given the differences in income and social setting, we will investigate if there is a difference in cognitive outcomes between children living in urban and rural areas in Uganda.

\section{Impairment specific factors contributing to cognitive functioning}

In the analysis we include spina bifida specific variables such as the presence of hydrocephalus, neurosurgical treatment, motor function, and incontinence management.

Hydrocephalus. The neuropsychological profile of persons with hydrocephalus is one of relative impairment, whether or not spina bifida is present. Shunt infections, revisions, and a history of seizures predict poorer memory (Dennis et al, 2007), meta-cognitive abilities, executive functioning (Tarazi, Zabel, \& Mahone, 2008), and cognitive health (Kulkarni et al, 2004). In a comparative study Hampton et al. (2011) found higher neurocognitive scores in children with spina bifida without hydrocephalus compared to children with SB and hydrocephalus. A stepwise pattern in terms of number of affected domains from the shunt-treated group to the arrested-hydrocephalus group to the no-hydrocephalus group was identified (Hampton et al., 2011). We expect to find the same stepwise patterns, with possibly larger effect sizes due to the limitations in access to early neurosurgery and regular physio- and occupational therapy. 
Neurosurgery. The majority of children with spina bifida and progressive hydrocephalus need neurosurgery. At the time of this study the initial surgery (closure of the spine) and ETV and VP-shunting for children with progressive hydrocephalus were only available in two public government funded hospitals (Mulago National Referral Hospital in Kampala and Mbarara Regional Referral Hospital), and one private specialized neuro-paediatric hospital (CURE Children's Hospital) in Mbale, eastern Uganda. Delay in neurosurgery has been associated with more neurodevelopmental delay (Warf et al., 2009). Shunts are sensitive to infection and malfunctioning (Hunt et al, 1999), and are related to epilepsy (Kulkarni et al, 2004). ETV is an alternative primary treatment for hydrocephalus and alternative for malfunctioning and infected shunts (Warf, 2005). Earlier Warf et al. found no differences between cognitive outcomes of infants aged 5 to 52 months treated with ETV and VP shunt treatment (Warf et al., 2009). We will evaluate the effect of type of neurosurgery on cognitive functioning in pre-primary and primary school aged children.

Gross and fine motor functioning. Gross and fine motor functioning are affected in children with spina bifida. Gross motor skills such as movement of the upper and lower limbs, and eyes are core deficits in children with spina bifida (Dennis et al., 2006). Children with spina bifida with extensive paralysis will often require a wheelchair, while others may be able to use crutches, braces, or walking frames. They benefit from physio- and occupational therapy (Abresch et al., 2007; Andren \& Grimby, 2000; Danielsson et al., 2008; Jansen et al, 2009). Children with spina bifida are prone to pressure sores and need regular skin checks to prevent these (Lindsay, 2014).

The majority of children with spina bifida have impaired fine motor function and visual-motor integration. Handwriting and drawing are the most affected skills (Feder \& Majnemer, 2007; Hetherington et al, 2006; Lindquist et al, 2008; Vinck et al., 2010).

We expect that children with better motor function have better participation in daily activities, including schooling, which will in turn improve cognitive functioning. 
Incontinence. Most have bowel and bladder problems. Clean Intermittent Catheterization (CIC) and bowel management techniques are used to keep the child dry and clean (IFSBH, 2014; Verpoorten \& Buyse, 2008). CIC and bowel management training in Uganda is offered by the four organizations which provide physical rehabilitative therapy. Through a CBR approach funded by private donors, children are followed up at home and are provided with low costs - if possible locally made - continence materials (Mertens \& Bannink, 2012).

We study continence as a possible important factor for inclusion, as we expect that good incontinence management results into increased participation in daily activities, including schooling. A child with not managed incontinence will have accidents and smell of urine, and is more likely to be socially excluded.

\section{Environmental factors contributing to cognitive functioning}

Schooling. Although inclusion of children with spina bifida in normal schools is common in high and middle income countries, this remains a challenge in low income countries (Chataika et al, 2012). Implementation of inclusive education in Sub Saharan Africa is affected negatively by nonsupportive attitudes of parents, teachers, and community members, distance to school, not conducive school environment (access, materials, equipment), and lack of trained teachers. The Ministry of Education and Sports in Uganda has an Universal Primary Education (UPE) and inclusive education policy for access and inclusion of children with special needs in primary schools (Nyende, 2012), however implementation of inclusive education remains limited at grass root level (Ejuu, 2016).

In our study we expect a large number of children to be out of school. In earlier findings parents of children with spina bifida indicated UPE schools and several private schools would not admit their child (Bannink et al, 2015). Of those in school, children reported being bullied about their physical appearance and learning speed (Bannink, Idro, \& Van Hove, 2016a). 
Children who are not schooling are likely to have lower cognitive outcomes and become socially more isolated as schooling itself has an effect on general cognitive development (Hunt, 2010; Sylva, 1994).

Social support. In high income countries family support has been identified as a factor contributing to cognitive functioning in children with spina bifida (Dennis et al., 2006; Fletcher et al., 2002). Having support increases the chances of access to remediation for specific cognitive and academic skills. Caregivers of children with disabilities in sub Saharan Africa often felt that they do not have sufficient time to cope with household tasks and feel isolated (Gona et al, 2011; Hartley et al, 2004). Families of children with neuro-disabilities including spina bifida in Kenya (van't Veer et al., 2008), Malawi (Paget et al, 2015), and South Africa (Coomer, 2013) struggle with the social barriers towards care and support for their child. In absence of health care and social services for children with disabilities in sub Saharan Africa, the children's families are often their main source of care and protection (Guyer, 1981; Miles, 2002).

We expect that cognitive outcomes of children with spina bifida are related to whether parents have support from another adult or support group or not. We believe that parents who feel supported, are more likely to stimulate their children at home, resulting into better cognitive outcomes of their children. In this study we will compare cognitive outcomes of children with spina bifida and their siblings. We will analyse which demographic (sex, gender, SES), spina bifida specific (hydrocephalus, neurosurgery, motor function, incontinence), and environmental factors (schooling and social support) predict cognitive functioning, and make recommendations for further studies and interventions in low resource settings.

\section{Method}

\section{Study design}

Purposeful sampling was used in Mbarara, Kampala, and Mbale where CURE holds bi-monthly clinics. CURE hospital and the partnering 
rehabilitation centers in Kampala and Mbarara were requested to list the children registered in their follow up programs, and inform them during home visits and through telephone calls to attend the clinic. In Gulu and Lira where no follow up system or registry of the children was in place at the time, radio announcements were aired to inform parents about the upcoming review clinic in the area, and specifically invited parents with children with spina bifida and hydrocephalus between the age of 4 and 14 years to attend.

Qualitative semi structured interviews and quantitative functioning scales measurements were combined and conducted between June 2011 and December 2014 with 133 parents, 133 children with spina bifida, and 35 siblings. The siblings were randomly selected from the 63 families living in the central region.

The assessments were held in the local language of the area, and a translator was hired and trained for each area to assist in conducting the assessment. Some of the interviews were conducted in English, if parents, children or teachers were fluent and requested for this.

\section{Ethical considerations}

Ethical approval and research clearance were obtained from Ghent University, Belgium, the Uganda Virus Research Institute, and the Uganda National Council for Science and Technology. Informed consent was obtained from all parents and teachers, and assent from children and siblings of 8 years and above where possible. Consent forms were translated into the local languages and discussed and agreed with the participant with assistance of a translator if the participant or child did not speak English.

\section{Selected measures}

Demographic and impairment specific variables such as the presence of hydrocephalus, neurosurgical treatment and rehabilitation services received, and incontinence management was collected from the parents for each child. Data on school going was collected and entered into a database.

Gross motor skills were assessed using basic measures on whether a child was able to sit or walk independently, and was using assistive devices. Fine motor skills were measured with the Vineland Adaptive Behaviour Scales 
(VABS) Daily Functioning Sub Scale and reflect both fine motor skills and daily functioning skills such as the ability to dress oneself, bath, and eat or drink independently. The reliability of the fine motor skill outcomes measure of the VABS was good with a Cronbach's Alpha of .82. The gross and fine motor skills measures were assessed by asking the parents about the child's functioning and observing the children's abilities.

To measure cognitive functioning, a set of cognitive subtests from existing tools was screened, selected for piloting, and administered (See Table 1).

Table 1

Psychometric Assessment Tools Screened, Piloted, and Administered

\begin{tabular}{lll}
\hline Tool screened & Selected for pilot & Administered \\
\hline $\begin{array}{l}\text { Picture Vocabulary Scale (PVS) - } \\
\text { adapted from the Kilifi Picture }\end{array}$ & PVS & PVS \\
$\begin{array}{l}\text { Vocabulary Test (Nampijja et al., } \\
\text { 2010) }\end{array}$ & & \\
$\begin{array}{l}\text { Kaufman Assessment Battery for } \\
\text { Children II - validated for }\end{array}$ & Hand movement & Hand movement \\
$\begin{array}{l}\text { Ugandan population (Bangirana et } \\
\text { al., 2009) - subtests selected }\end{array}$ & Number recall Triangles & Block counting \\
$\begin{array}{l}\text { Wechsler Intelligence Scale for } \\
\text { Children IV (Wechsler, 2003) - } \\
\text { subtests selected }\end{array}$ & Picture Concepts Matrix & \\
& Reasoning Digit Span, & \\
$\begin{array}{l}\text { Block Design - adapted from the } \\
\text { British Ability Scales (Nampijja } \\
\text { al., 2010) }\end{array}$ & Block design & \\
$\begin{array}{l}\text { Halstead-Reitan } \\
\text { Neuropsychological Battery - } \\
\text { progressive figures and trail- } \\
\text { making (Reitan, 1985) }\end{array}$ & Progressive Figures & \\
& & \\
\hline
\end{tabular}


Table 1 Continued

\begin{tabular}{lcc}
\hline Total screened & Selected for pilot & Administered \\
\hline Visual Motor Integration Test & VMI & VMI \\
(VMI)- visual perception / motor & & \\
integration (Beery, Buktenica, \& & & \\
Beery, 1989) & & \\
\hline
\end{tabular}

Cross-cultural application of neurocognitive assessments has been studied, and assessment batteries have been adapted for sub-Saharan African settings including Uganda, the majority in HIV and malaria studies (Abubakar et al., 2008; Alcock et al, 2008; Bangirana et al., 2009; Bangirana et al, 2015; Boivin, 2002; Holding et al., 2004; Nampijja et al., 2010). The pilot of psychometric assessment tools took place in a group of 12 children in Kampala. Most assessment batteries were difficult to complete, and its cultural adequacy could be questioned. Based on the pilot, we selected subscales which were understood and were culturally relevant. The Picture Vocabulary scale works with pictures relevant to the Kenyan and Ugandan context, and the block design test was simplified using wooden blocks by Nampijja et al (2010). The other tests were not adapted, but deemed fit for use in the Ugandan context. The subscales were combined and administered to all children. On average the cognitive assessments took 1.5 hours. Assessments took place at the rehabilitation sites or the child's home.

\section{Data manage ment}

Basic demographic, impairment, schooling data, and records of the cognitive, gross and fine motor scores were written out during assessments, and entered into a SPSS database after completion. Demographic data included age, gender, religion, location, socio-economic status, parental education, occupation, and marital status. Impairment specific variables included were the presence of hydrocephalus, neurosurgical treatment and rehabilitation services received, incontinence status, and incontinence management. Information on schooling, class, and performance was collected for each child. Motor and cognitive outcomes were entered in 
handheld assessment scales, and entered into a password protected database. Study files were filed in a lockable cupboard.

\section{Data Analysis}

The sub-total scores for the VABS subscale were calculated to compare means of the scores between the children with spina bifida and their siblings using SPSS16. Confirmatory factor analysis was carried out to investigate whether all cognitive subtests could be represented by a single underlying cognitive ability factor. Not all children were able to carry out all the subtests. Within the confirmatory factor model global cognitive functioning was estimated on the basis of those tests that were completed by each child.

ANCOVA was used to test for significant differences in cognitive scores between children and siblings using age as a covariate. The overall ability scores estimated on the basis of the confirmatory factor analysis was used as dependent variable.

Factors predicting inter-individual differences in cognitive functioning within the spina bifida group were investigated by regression analysis with a forward selection procedure. Because of its importance in predicting cognitive functioning, it was further investigated which factors predicted schooling and motor functioning using logistic regression and multivariate regression respectively.

\section{Sample description}

The study population consisted of 133 children with spina bifida (myelomeningocele type) $(59.4 \%$ male, $40.6 \%$ female) of which 60 with spina bifida and hydrocephalus; 133 parents; 35 siblings (21 female, 14 male); and 30 teachers ( 22 female, 8 male) of children with spina bifida. Table 2 describes the demographics of the study population. 
IJEP - International Journal of Educational Psychology, 5(3) 261

Table 2

Demographic Characteristics ( $N=133$ children with spina bifida, $N=35$ siblings)

\begin{tabular}{|c|c|c|c|c|}
\hline Variable & Child & $\%$ & Sibling & $\%$ \\
\hline \multicolumn{5}{|l|}{ Gender child } \\
\hline Male & 79 & $59.4 \%$ & 14 & $40.00 \%$ \\
\hline Female & 54 & $40.6 \%$ & 21 & $60.00 \%$ \\
\hline \multicolumn{5}{|l|}{ Child is schooling in } \\
\hline Nursery school & 48 & $36.1 \%$ & 0 & \\
\hline Primary school & 22 & $16.5 \%$ & 9 & $25.70 \%$ \\
\hline Secondary school & 4 & $3.0 \%$ & 26 & $74.30 \%$ \\
\hline Not schooling & 59 & $44.4 \%$ & 0 & \\
\hline \multicolumn{5}{|l|}{ Type of disability } \\
\hline Spina bifida & 73 & $54.9 \%$ & 0 & \\
\hline Spina bifida and hydrocephalus & 60 & $45.1 \%$ & 0 & \\
\hline \multicolumn{5}{|l|}{ Location / region } \\
\hline Central & 63 & $47.4 \%$ & 35 & $100 \%$ \\
\hline East & 26 & $17.3 \%$ & 0 & \\
\hline West & 29 & $21.1 \%$ & 0 & \\
\hline North & 19 & $14.3 \%$ & 0 & \\
\hline \multicolumn{5}{|l|}{ Religion } \\
\hline Christian & 100 & $77.5 \%$ & 32 & $80.0 \%$ \\
\hline Muslim & 26 & $20.2 \%$ & 6 & $17.1 \%$ \\
\hline Other & 13 & $2.3 \%$ & 1 & $2.9 \%$ \\
\hline \multicolumn{5}{|l|}{ Relationship parent } \\
\hline Mother & 104 & $78.2 \%$ & 26 & $74.3 \%$ \\
\hline Father & 14 & $10.5 \%$ & 6 & $17.1 \%$ \\
\hline Grandmother & 9 & $6.8 \%$ & 2 & $5.7 \%$ \\
\hline Other & 6 & $4.5 \%$ & 1 & $2.9 \%$ \\
\hline
\end{tabular}


262 Bannink et al. - Cognitive Abilities

Table 2 Continued

\begin{tabular}{lllll}
\hline Variable & Child & $\%$ & Sibling & $\%$ \\
\hline
\end{tabular}

Education level parent

None

$\begin{array}{cccc}6 & 4.7 \% & 3 & 8.6 \% \\ 72 & 56.7 \% & 22 & 62.9 \% \\ 28 & 22.0 \% & 6 & 17.1 \% \\ 11 & 8.7 \% & 1 & 2.9 \% \\ 10 & 7.9 \% & 3 & 8.6 \%\end{array}$

Marital status parent

Single

Married

Separated

Widowed

Monthly household income

$$
\begin{aligned}
& <30 \text { euro } \\
& 30-60 \text { euro } \\
& 61-90 \text { euro } \\
& >90 \text { euro }
\end{aligned}
$$

Occupation parent

Finance / adminis tration

Small scale private business

Teacher / education

Medical / paramedical

Civil service / government

Peas ant farmer

No occupation

$\begin{array}{cccc}12 & 9.2 \% & 0 & \\ 101 & 75.6 \% & 26 & 74.3 \% \\ 9 & 6.9 \% & 6 & 17.1 \% \\ 11 & 8.4 \% & 3 & 8.6 \%\end{array}$

25

28

26

48

\begin{tabular}{cccc}
5 & $3.8 \%$ & 2 & $5.9 \%$ \\
30 & $22.7 \%$ & 7 & $11.8 \%$ \\
9 & $6.8 \%$ & 3 & $8.6 \%$ \\
5 & $3.8 \%$ & & \\
2 & $1.5 \%$ & & \\
65 & $49.2 \%$ & 19 & $62.9 \%$ \\
6 & $12.1 \%$ & 3 & $8.6 \%$ \\
\hline
\end{tabular}


The average age of the children with spina bifida was $6.1(\mathrm{SD}=2.04)$, and 7.8 years $(\mathrm{SD}=2.53)$ for siblings. The majority of the children with spina bifida $(122,91.7 \%)$ had undergone surgery to close their spine (myelomeningocele closure) earlier in life. Whilst we looked for children in communities using radio announcements and searches through community leaders, we did not find more children who had not undergone surgery. We think that the majority who did not access neurosurgery died, as the initial surgery is key to survival in spina bifida. Of the 60 children who had both spina bifida and hydrocephalus, 25 (41.7\%) had undergone endoscopic third ventriculostomy while $12(20.0 \%)$ had ventriculo-peritoneal shunts placed. Here too, we could not find more children who had undergone VP shunt placement, which could be attributed to the high infection and mortality risks associated with this type of treatment in a low resource setting like Uganda. During our study 3 children died from the complications of shunt malfunctioning. The majority of parents took their children $(123,92.5 \%)$ for rehabilitation services such as physio- and occupational therapy.

Parents' ages ranged from 24 to 46 years with an average age of 32.9 (SD 5.2) years. About a third, $31.8 \%$ (42) of the parents did not have support from another adult or parents support group.

The household size ranged from 2 to 13 with an average of 6.5 persons per household ( $\mathrm{SD}=2.49$ ), with on average 4.3 children (SD 2.2) and 2.3 adults (SD 1.0) per household. The average monthly household income was 82 euro (range 12 to 604 euro). In total 63 families resided in the capital city and surrounding urban areas (47.4\%), whilst 52.6\% (70) lived in rural areas.

In total 54 children with spina bifida who were not in school, 74 children with spina bifida who were schooling, and 35 siblings who were schooling were included in the analysis of cognitive outcomes.

Gross motor skill outcomes of children with spina bifida were grouped into 4 groups: 58 children who can sit and walk (43.6\%), 36 children who can sit, and use assistive devices to walk (27.1\%), 37 children who can sit, not walk and do not use assistive devices to ambulate (27.8\%), and 2 children who could not sit nor walk and are not using assistive devices $(1.5 \%)$.

In total 106 children (79.7\%) with spina bifida were incontinent; 97 of them used CIC. The continence factor was dichotomized by grouping 
children who were using CIC and bowel management together and comparing them to 25 children who do not use continence management

\section{Results}

\section{Cognitive test battery}

Confirmatory factor analysis was carried out on the seven subtests. The onefactor model fitted the data well $\left(\chi^{2}=24.04, d f=14, p=.034, \chi^{2} / \mathrm{df}=1.72\right.$, RMSEA $=.07, \mathrm{CFI}=.96$, SRMR $=.04$. Table 3 shows the standardized factor loadings of each subtest. All subtests had high factors loadings (>.70).

Table 3

Confirmatory Factor Analysis of Cognitive Measures

\begin{tabular}{lc}
\hline Cognitive Sub Test & Fit factor loading \\
\hline Picture Vocabulary Scale total score - measures verbal cognitive & \\
ability & .70 \\
Block Design total score - measures spatial ability & .99 \\
Block Count total score - measures visual processing & .89 \\
Hand movement - measures short term memory / sequential & .98 \\
processing & \\
Number recall - measures short term memory / sequential & .96 \\
processing & \\
Visual Motor Integration - measures motor output skills & .83 \\
coordination & \\
Visual Motor Integration - measures visual perception input & .79 \\
skills
\end{tabular}

\section{Cognitive outcomes in children with spina bifida with their siblings}

An Analysis of Covariance with overall cognitive functioning as dependent variable, group (siblings, schooled children with spina bifida, and nonschooled children with spina bifida) and sex as independent variables, and 
age and socio-economical status (income) as covariates showed a significant and strong group effect $\left[F(2,145)=17.34, p<.001\right.$, partial $\left.\eta^{2}=.193\right]$. There was no significant effect of $\operatorname{sex}\left[F(1,145)=0.56, p=.456\right.$, partial $\left.\eta^{2}=.004\right]$ and no significant interaction effect between sex and group $[F(2,145)=$ $0.291, p=.748$, partial $\left.\eta^{2}=.004\right]$. Moreover, both covariates were significant $\left[F(1,145)=43.650, p<.001\right.$, partial $\eta^{2}=.231$ for age and $F(1,145)=7.165 p=.008$, partial $\left.\eta^{2}=.047\right]$. Table 4 summarizes the mean scores and standard errors.

Table 4

Cognitive Outcomes for Schooling and Not Schooling Children With Spina Bifida and Siblings Controlled for Age and Household Income

\begin{tabular}{lcccc}
\hline & & Mean & Std. Error & CI (min $-\max )$ \\
\hline Child with & Male & -1.104 & .348 & -1.793 to -.415 \\
spina bifida & Female & -1.081 & .391 & -1.854 to -.308 \\
not schooling & & & & \\
\hline Child with & Male & .014 & .268 & -.515 to- .543 \\
spina bifida & Female & .519 & .334 & -.140 to 1.179 \\
schooling & & & & .386 to 2.292 \\
\hline Sibling & Male & 1.339 & .482 & .688 to 2.312 \\
schooling & Female & 1.500 & .411 & \\
\hline
\end{tabular}

Note. Covariates appearing in the model were evaluated at the following values: age child $=6.5687$, household income $=2.71$.

Siblings of children with spina bifida had better cognitive outcomes compared to their schooling brothers and sisters with spina bifida, whilst children with spina bifida enrolled in school had better cognitive outcomes compared to children with spina bifida not enrolled in school. No significant gender differences were found. 


\section{Factors related to differences in cognitive functioning of children with spina bifida}

To investigate the predictors of inter-individual differences in cognitive functioning within the group of children with spina bifida, a regression analysis was executed with forward selection procedure with age, sex, impairment (e.g. spina bifida alone or spina bifida and hydrocephalus), type of treatment received for those with hydrocephalus (ETV or VP shunts), continence, household income, geographical region, education level parents, and support received by parent as possible predictors. Only four predictors were selected for cognitive functioning on the basis of this forward selection regression procedure (fine motor skills, age, schooling, and income). These four predictors accounted for $50.4 \%$ of the total variance in cognitive functioning. Older children with better fine motor skills, who were schooling and came from households with higher household income had significantly better cognitive functioning (see Table 5).

Table 5

Selected Predictors for Cognitive Functioning

\begin{tabular}{lll}
\hline Predictors & $B$ & \\
\hline Fine motor skills & .194 & $.390^{* *}$ \\
Age child & .294 & $.271^{* *}$ \\
Schooling & .942 & $.210^{* *}$ \\
Household income & .304 & $.153^{*}$ \\
\hline
\end{tabular}

Note. $* \mathrm{p}<.05, * * \mathrm{p}<.001$

Because of the importance of schooling and motor skills, we have further explored which factors predict schooling and these motor skills. To investigate the predictors of whether children with spina bifida were schooled or not, a logistic regression was executed with a forward selection procedure with age, sex, impairment (e.g. spina bifida alone or spina bifida and hydrocephalus), type of treatment received for those with hydrocephalus (ETV or VP shunts), continence, household income, geographical region, level parents, and support received by parent as possible predictors. Only 
three predictors were selected. The older the child $(\operatorname{Exp}(B)=1.595$, Wald $=$ $10.692, \mathrm{p}<.001]$, the higher the household income of the parents $(\operatorname{Exp}(\mathrm{B})=$ 1.869 , Wald $=9.087, \mathrm{p}=.003$ ], and the better the fine motor functioning $(\operatorname{Exp}(\mathrm{B})=1.235$, Wald $=15.338, \mathrm{p}<.001]$ the more likely the children with spina bifida was going to school.

To investigate the predictors of fine motor functioning among children with spina bifida a multivariate regression analysis was executed with a forward selection procedure with age, sex, impairment (e.g. spina bifida alone or spina bifida and hydrocephalus), type of treatment received for those with hydrocephalus (ETV or VP shunts), household income, geographical region, educational level parents, and support received by parent as possible predictors. Three significant predictors were identified: age, parental support and impairment. These three predictors accounted for $19.6 \%$ of the variance in fine motor functioning. The older the child $(\beta=.309)$, parents having social support $(\beta=.246)$, and children without hydrocephalus $(\beta=.214)$ had significantly better fine motor skills $\left[F(3,128)=10.408, p<.001, \mathrm{R}^{2} .196\right]$.

Moreover, fine motor skills were also significantly correlated with gross motor skills $(r=.616, p<.001)$ and with continence $(r=.405, p<.001)$. A multivariate and a logistic regression analysis with a forward selection procedure using the same predictors as for fine motor functioning identified similar predictors for gross motor skills and continence respectively. The older the child $(\beta=.216)$, parents having social support $(\beta=.210)$, and children without hydrocephalus $(\beta=.267)$ had significantly better gross motor skills $\left[\mathrm{F}(3,129)=7.805, \mathrm{p}<.001, \mathrm{R}^{2} .154\right]$. When parents could rely on social support $[\operatorname{Exp}(\mathrm{B})=3.420$, Wald $=3.383, \mathrm{p}=.012]$ and when parents had a higher income $[\operatorname{Exp}(\mathrm{B})=1.900$, Wald $=8.036, \mathrm{p}=.005]$ children were more likely to be continent or manage their continence.

\section{Discussion and conclusion}

\section{Cognitive testing}

Environmental factors play a key role in the cognitive function of children with spina bifida in Uganda. Earlier Bangirana et al. (2009, 2015) and 
Nampijja et al. (2010) have provided evidence for successful adaptation of assessment batteries for Ugandan children taking cultural factors into consideration. Despite the cultural sensitivity of some of these instruments, most of these assessment tools were too challenging to complete for the children with spina bifida due to motor difficulties. To mitigate this, we did not apply tests which were too difficult from a motor perspective, and estimated cognitive functioning on the basis of less challenging test. No speed tests were applied which enabled children with lower motor ability to take their time to answer the questions. Despite the adjustments made and testing the pilot in the central region, a number of children in the study group could still not perform the procedures. In some cases observations during the cognitive testing indicated that non-responding was caused by feeling shy rather than being unable to complete the tests. This mainly concerned children who were not schooling and were from rural areas where they lived in rather remote areas.

We do not have a comparable assessment tool to look at effect size between high income countries and our findings. However from the high number of children who could not complete the culturally and impairment specific testing set, we may conclude that the level of cognitive functioning was lower compared to high income countries.

\section{Cognitive outcomes in children with spina bifida and their siblings}

Children with spina bifida in Uganda had lower cognitive outcomes compared to their schooling siblings. This is in line with earlier studies in which children with spina bifida have lower scores on visual perception, language comprehension, attention, processing and memory tasks compared to their peers (Dennis \& Barnes, 2010; Dennis et al., 2007; Rose \& Holmbeck, 2007). Hampton et al (2011) found differences of 13 to 20 points in IQ scores in children with spina bifida. In our study we did not have Ugandan population norms which would allow us to precisely estimate the size of effects in terms of IQ points. Cognitive outcomes in our study population were predicted by age, household income, motor functioning, and schooling. 


\section{Demographic factors contributing to cognitive functioning}

As expected age had an evident effect on cognitive functioning. No significant differences were found between boys and girls, which is in line with earlier studies of cognitive functioning in Ugandan children (Nampijja et al., 2010). Children from rural and urban areas had similar cognitive outcomes.

Household income was a main factor in predicting cognitive outcomes. Interestingly parental education or social economical status did not predict cognitive outcomes, but household income did. Having sufficient income to send children to school and access rehabilitative care, is key in a low resource setting with limited public services. Earlier we found that parents would not prioritize sending their child with spina bifida to school if they did not have sufficient funds to send all children to school (Bannink, Idro, \& Van Hove, 2016b).

\section{Impairment specific factors contributing to cognitive functioning}

Motor function. Children with better motor function had higher cognitive functioning scores. Although children with good gross and fine motor skills are expected to score higher on cognitive tests which require fine motor skills such as block designs, and the visual motor integration drawing tasks (Raghubar et al., 2015), we believe this result is not a direct effect.

No timed tests were administered and if a child could not complete a subtest, this was adjusted for, leaving out negative impacts on the total cognitive outcomes scores. Instead we believe children who have better motor function are more likely to participate in daily activities, and be stimulated through these, resulting in better cognitive development.

Parental support and household income were important predictors for continence management. If parents feel supported, they may be more likely and able to carry out CIC several times a day. This in turn will help improve quality of life; earlier better motor function and continence management were related to better quality of life in Kenya (van't Veer et al., 2008). Higher household income would help with covering travel costs to rehabilitation centers for supplies of catheters. 
Hydrocephalus. The type of impairment, neurosurgery or rehabilitation services the children received did not affect the cognitive outcomes in children in our study. In earlier findings Ugandan infants not requiring treatment for hydrocephalus had significantly better neurocognitive outcomes compared to those who did require treatment, but no differences were found between cognitive outcomes of infants treated with ETV and VP shunt treatment (Warf et al., 2009). We did not find significant differences between children with and without hydrocephalus controlled for fine motor development. However hydrocephalus did predict motor function, which significantly contributes to cognitive outcomes, indicating an indirect effect. Hampton et al (2011) found lower cognitive outcomes in children with spina bifida and hydrocephalus compared to children with spina bifida alone.

It is possible that our sample was too small to find any direct effect, or that the effect is reduced as other factors in our setting are more important, e.g. having sufficient income, and better motor functioning and going to school. The effect of the presence of hydrocephalus and type of surgery may not weigh sufficiently in a setting where a child is not being schooled or has not access to rehabilitative care.

\section{Environmental factors contributing to cognitive functioning}

Schooling. Children with spina bifida enrolled in school had better cognitive outcomes compared to children with spina bifida not enrolled in school.Schooling was predicted by age, household income, and motor functioning. When controlling for motor function and income, schooling still had a significant effect on cognitive functioning. This pleads for increasing school enrolment and inclusion.

In total $58.7 \%$ of the children with spina bifida in our study were in school. This is low compared to the national net enrolment ratio for primary school of $94.5 \%$ (Government of Uganda, 2013), but high compared to the UNICEF study in which only $9 \%$ of children with disabilities were enrolled in school (UNICEF, 2014). It should be noted that this last study provided a percentage for children with all types of impairments. Whilst children with spina bifida have cognitive functioning deficits, they generally are able to enrol and participate in school and follow the national curriculum material. As well our study mainly included children who had received neurosurgery 
and may have been more likely to survive, receive care, and enrol in school compared to a child with cerebral palsy or intellectual disability.

Parental support. Aside the positive effect of schooling on cognitive outcomes, we believe that having support and more income, directly affects the child. Most likely parents who receive social support and have a higher income, have more time to take their children for physical rehabilitation, and provide direct stimulation at home, which stimulates the motor and cognitive development, and CIC. They may equally have more funds to purchased mobility devices and physiotherapy compared to parents with lower incomes. Even in high income countries, physical impairment outcomes such as continence, and community ambulation are lower in groups without private insurance (Schechter et al, 2015).

\section{Limitations}

Limitations of our study included purposeful selection of participants. Despite radio announcements and searches for children with spina bifida in the communities by local leaders, we did not find any children who had not received neurosurgery and rehabilitation. Most likely those who did not receive this died. The children who participated in our study may have therefore only represented those who did 'better' or did not have shunt infections, resulting in overly positive cognitive outcomes.

Another limitation was the lack of a validated and normed cognitive assessment tool for Ugandan children with spina bifida to define cognitive assets and deficits in detail and make recommendations on neurocognitive learning goals. The impact of medical factors such as Chiara II malformation could not be included in the study as information and imaging facilities were not available. The number of siblings included in the study was limited due to logistic constraints in follow up of children upcountry. 


\section{Implications for future studies and interventions}

In future a cohort study following children from birth is recommended to understand mortality, survival, and motor and cognitive development in relation to their environment and rehabilitation care received. In future studies we recommend selecting families in one or two geographical areas and follow the child, siblings, parents, and other caregivers over time.

The feasibility and meaning of performing psychometric procedures in children with severe impairment has been questioned (Fletcher, 2014). We found difficulties in assessing children from rural areas who lived isolated lives and would not answer questions. We equally struggled to find appropriate tests which could be completed by children with spina bifida. Fletcher, Barnes and Dennis (2002) have argued for the use of adaptive behaviour assessments as a supplement to cognitive neuropsychological assessments and more studies on how environmental factors affect cognitive functioning providing approaches to enhance outcomes (Dennis et al, 2006; Fletcher, 2014). Building on this, and our findings which indicate the importance of household income, motor function, and parental support we argue for awareness raising on the cognitive profiles of children with spina bifida and develop low costs strategies to help them in learning, and providing parental support.

Livelihood support to increase household income will be a key strategy to increase access to services and improve cognitive functioning in the long run. Successful approaches reported by non governmental and governmental programs have included village savings and loan associations and small scaled capacity building programs, and could target more families of children with disabilities (Government of Uganda, 2014; NUDIPU, 2016; USAID \& AVSI, 2016).

We argue for implementation of public health community based rehabilitative services. Despite policies in place, none of the families in our study access governmental CBR services. Better referral networks from public facilities where $\mathrm{CBR}$ is lacking to private facilities is recommended to ensure children receive rehabilitative therapy.

Lastly but most importantly we argue for more support for parents as parental support improves children's outcomes in the long run: from better motor skills to school enrolment and better cognitive outcomes. This support 
can consist of the presence of another adult in the home to help in daily tasks, but also of a peer support group to discuss care and challenges with other parents with spina bifida. The International Federation for Spina Bifida and Hydrocephalus (IF) had such support groups in place and encourages set up and support of new groups in low resource countries (Mertens \& Bannink, 2012). Further use and support of such groups can enhance the future education outcomes of the children.

By ensuring a holistic approach for children with spina bifida and their families, involving the physio-, and occupational therapist in community based rehabilitation to develop fine and gross motor skills; making sure parents receive social support and improve their livelihoods so that children can go to school; cognitive outcomes can improve over time.

\section{Acknowledgements}

The authors thank all parents of children with spina bifida and hydrocephalus, staff of Cure Children's Hospital Uganda, Gulu Regional Orthopaedic Workshop and Rehabilitation Center / AVSI Foundation, Katalemwa Cheshire Home, and Our Useful Rehabilitation Services for their participation in this study. Our gratitude goes to the International Federation for Spina Bifida and Hydrocephalus, and the IF Uganda office for their support.

\section{References}

Abresch, R. T., McDonald, D. A., Widman, L. M., McGinnis, K., \& Hickey, K. J. (2007). Impact of spinal cord dysfunction and obesity on the health-related quality of life of children and adolescents. $J$ Spinal Cord Med, 30 Suppl 1, S112-118. doi:

10.1080/10790268.2007.11754614

Abubakar, A., Van de Vijver, F., Van Baar, A., Mbonani, L., Kalu, R.,

Newton, C., \& Holding, P. (2008). Socioeconomic status, anthropometric status, and psychomotor development of Kenyan children from resource-limited settings: a path-analytic study. Early human development, 84(9), 613-621. doi:

10.1016/j.earlhumdev.2008.02.003

Alcock, K. J., Holding, P., Mung'ala-Odera, V., \& Newton, C. (2008).

Constructing tests of cognitive abilities for schooled and unschooled children. Journal of Cross-Cultural Psychology, 39(5), 529-551. doi:10.1177/0022022108321176 
Andren, E., \& Grimby, G. (2000). Dependence and perceived difficulty in activities of daily living in adults with cerebral palsy and spina bifida. [Clinical Trial Comparative Study Research Support, NonU.S. Gov't]. Disabil Rehabil, 22(7), 299-307. doi: 10.1080/096382800296656

Bangirana, P., Seggane, M., Allebeck, P., Giordani, B., John, C. C., Opoka, O. R., ... Boivin, M. J. (2009). A preliminary examination of the construct validity of the KABC-II in Ugandan children with a history of cerebral malaria. [Research Support, N.I.H., Extramural Research Support, Non-U.S. Gov't]. Afr Health Sci, 9(3), 186-192.

Bangirana, P., Sikorskii, A., Giordani, B., Nakasujja, N., \& Boivin, M. J. (2015). Validation of the CogState battery for rapid neurocognitive assessment in Ugandan school age children. Child Adolesc Psychiatry Ment Health, 9, 38. doi: 10.1186/s13034-015-0063-6

Bannink, F., Idro, R., \& Van Hove, G. (2016a). 'I like to play with my friends' children with spina bifida and belonging in Uganda. Social Inclusion, 4(1), 14. doi: 10.17645/si.v4i1.630

Bannink, F., Idro, R., \& Van Hove, G. (2016b). Teachers' and parents' perspectives on inclusive education for children with spina bifida in Uganda. Journal of Childhood \& Developmental Disorders 2(2). doi: 10.4172/2472-1786.100026

Bannink, F., Stroeken, K., Idro, R., \& Van Hove, G. (2015). Community Knowledge, Beliefs, Attitudes, and Practices towards Children with Spina Bifida and Hydrocephalus in Uganda. International Journal of Disability, Development and Education, 62(2), 182-201. doi: 10.1080/1034912x.2014.998174

Boivin, M. J. (2002). Effects of early cerebral malaria on cognitive ability in Senegalese children. Journal of Developmental \& Behavioral Pediatrics, 23(5), 353-364. doi: 10.1097/00004703-20021000000010

Chataika, T., McKenzie, J. A., Swart, E., \& Lyner-Cleophas, M. (2012). Access to education in Africa: responding to the United Nations Convention on the Rights of Persons with Disabilities. Disability \& Society, 27(3), 385-398. doi: 10.1080/09687599.2012.654989 
Coomer, R. A. (2013). The experiences of parents of children with mental disability regarding access to mental health care. Afr J Psychiatry (Johannesbg), 16(4), 271-276. doi: 10.4314/ajpsy.v16i4.36

CURE. (2008). Caretaker's Information Kit. Pennsylvania: CURE Children's Hospital of Uganda and York College, Department of Nursing.

Danielsson, A. J., Bartonek, A., Levey, E., McHale, K., Sponseller, P., \& Saraste, H. (2008). Associations between orthopaedic findings, ambulation and health-related quality of life in children with myelomeningocele. J Child Orthop, 2(1), 45-54. doi:

10.1007/s11832-007-0069-6

Dennis, M., \& Barnes, M. A. (2010). The cognitive phenotype of spina bifida meningomyelocele. Developmental Disabilities(16), 9. doi: $10.1002 / \mathrm{mrdd} .89$

Dennis, M., Jewell, D., Drake, J., Misakyan, T., Spiegler, B., Hetherington, R., ... Barnes, M. (2007). Prospective, declarative, and nondeclarative memory in young adults with spina bifida. [Research Support, N.I.H., Extramural Research Support, Non-U.S. Gov't]. J Int Neuropsychol Soc, 13(2), 312-323. doi:

$10.1017 / \mathrm{S} 1355617707070336$

Dennis, M., Landry, S. H., Barnes, M., \& Fletcher, J. M. (2006). A model of neurocognitive function in spina bifida over the life span. Journal of the International Neuropsychological Society, 12(02), 285-296. doi: $10.1017 /$ S1355617706060371

Ejuu, G. (2016). Moving in Circles along a Straight Path: The Elusiveness of Inclusive Education in Early Childhood Development in Uganda. Journal of Childhood \& Developmental Disorders, 2(1). doi: 10.4172/2472-1786.100009

Feder, K. P., \& Majnemer, A. (2007). Handwriting development, competency, and intervention. Developmental Medicine \& Child Neurology, 49(4), 312-317. doi: 10.1111/j.1469-8749.2007.00312.x Fletcher, J. M. (2014). Alternative Approaches to Outcomes Assessment: Beyond Psychometric Tests. Pediatr Blood Cancer, 61(10), 17341738. doi: $10.1002 / p b c .24824$

Fletcher, J. M., Barnes, M., \& Dennis, M. (2002). Language development in children with spina bifida. [Research Support, U.S. Gov't, P.H.S. 
Review]. Semin Pediatr Neurol, 9(3), 201-208. doi: 10.1053/spen.2002.35500

Gona, J. K., Mung'ala-Odera, V., Newton, C. R., \& Hartley, S. (2011).

Caring for children with disabilities in Kilifi, Kenya: what is the carer's experience? [Research Support, Non-U.S. Gov't]. Child Care Health Dev, 37(2), 175-183. doi: 10.1111/j.1365-2214.2010.01124.x Government of Uganda (2014). National Agricultural Advisory Services Programme (NAADS) Progress Report 2013/14 Retrieved March 8, 2015.

Guyer, J. I. (1981). Household and community in African studies. African Studies Review, 87-137. doi: 10.2307/523903

Halpern, D. F. (2013). Sex differences in cognitive abilities. NY: Taylor and Francis.

Hampton, L. H., Fletcher, J. M., Cirino, P., Blaser, S., Kramer, L. A., Drake, J., \& Dennis, M. (2011). Hydrocephalus status in spina bifida: an evaluation of variations in neuropsychological outcomes. Journal of Neurosurgery: Pediatrics, 8(3), 289-298. doi: 10.3171/2011.6.PEDS10584

Hartley, S., Ojwang, P., Baguwema, A., Ddamulira, M., \& Chavuta, A. (2004). How do carers of disabled cope? The ugandan perspective. Child: care, health and development, 31(2), 14. doi: 10.1111/j.13652214.2004.00464.x

Hetherington, R., Dennis, M., Barnes, M., Drake, J., \& Gentili, F. (2006).

Functional outcome in young adults with spina bifida and hydrocephalus. Child's Nervous System, 22(2), 117-124. doi: 10.1007/s00381-005-1231-4

Holding, P. A., Taylor, H. G., Kazungu, S. D., Mkala, T., Gona, J., Mwamuye, B., . . . Stevenson, J. (2004). Assessing cognitive outcomes in a rural African population: development of a neuropsychological battery in Kilifi District, Kenya. Journal of the International Neuropsychological Society, 10(02), 246-260. doi: $10.1017 / \mathrm{s} 1355617704102166$

Hunt, E. (2010). Human intelligence. Cambridge: Cambridge University Press. 
IFSBH (Producer). (2014, October 26 2015). Spina Bifida - Fact Sheet. [Information Material] Retrieved from

http://www.ifglobal.org/images/documents/IF_SB_factsheet.pdf

Jansen, H., Blokland, E., de Jong, C., Greving, J., \& Poenaru, D. (2009).

Quality of life of African children with spina bifida: results of a validated instrument. Cerebrospinal Fluid Research, 6(Suppl 2), S25. doi: 10.1186/1743-8454-6-s2-s25

Lindquist, B., Persson, E. K., Uvebrant, P., \& Carlsson, G. (2008). Learning, memory and executive functions in children with hydrocephalus. [Research Support, Non-U.S. Gov't]. Acta Paediatr, 97(5), 596-601. doi: 10.1111/j.1651-2227.2008.00747.x

Lindsay, S. (2014). A Qualitative Synthesis of Adolescents' Experiences of Living With Spina Bifida. Qualitative Health Research, 24(9), 1298-1309. doi: $10.1177 / 1049732314546558$

Mertens, P., \& Bannink, F. (2012). Interdisciplinary care for children with spina bifida in east and southern Africa. Journal of Medicine and the Person, 10(3), 129-135. doi: 10.1007/s 12682-012-0126-x

Miles, M. (2002). Children with spina bifida and hydrocephalus in East Africa: can family and community resources improve the odds? Disability \& Society, 17, 15. doi: 10.1080/0968759022000010425

Nampiija, M., Apule, B., Lule, S., Akurut, H., Muhangi, L., Elliott, A. M., \& Alcock, K. J. (2010). Adaptation of Western measures of cognition for assessing 5-year-old semi-urban Ugandan children. British Journal of Educational Psychology, 80(1), 15-30. doi: 10.1348/000709909x460600

Northrup, H., \& Volcik, K. A. (2000). Spina bifida and other neural tube defects. [Review]. Curr Probl Pediatr, 30(10), 313-332. PMID: 11147289

NUDIPU. (2016). National Union of Disabled Persons of Uganda. Retrieved December 12, 2015

Nyende, F. (2012). Children with Disabilities in Universal Primary Education in Uganda: A Rights-Based Analysis to Inclusive Education. The Hague: Institute of Social Studies.

Paget, A., Mallewa, M., Chinguo, D., Mahebere-Chirambo, C., \& Gladstone, M. (2015). "It means you are grounded" - caregivers' perspectives on 
the rehabilitation of children with neurodisability in Malawi. Disabil Rehabil, 1-12. doi: 10.3109/09638288.2015.1035458

Pike, M., Swank, P., Taylor, H., Landry, S., \& Barnes, M. A. (2013). Effect of Preschool Working Memory, Language, and Narrative Abilities on Inferential Comprehension at School-Age in Children with Spina Bifida Myelomeningocele and Typically Developing Children. Journal of the International Neuropsychological Society, 19(04), 390-399. doi: 10.1017/S1355617712001579

Raghubar, K. P., Barnes, M. A., Dennis, M., Cirino, P. T., Taylor, H., \& Landry, S. (2015). Neurocognitive predictors of mathematical processing in school-aged children with spina bifida and their typically developing peers: Attention, working memory, and fine motor skills. Neuropsychology, 29(6), 861-873. doi:

10.1037/neu0000196

Rose, B. M., \& Holmbeck, G. N. (2007). Attention and executive functions in adolescents with spina bifida. [Research Support, N.I.H., Extramural Research Support, Non-U.S. Gov't]. J Pediatr Psychol, 32(8), 983-994. doi: 10.1093/jpepsy/jsm042

Schechter, M. S., Liu, T., Swanson, M., Ward, E., \& Thibadeau, J. (2015). Sociodemographic Attributes and Spina Bifida Outcomes. Pediatrics, 135(4), e957-e964. doi:10.1542/peds.2014-2576

Strand, S., Deary, I. J., \& Smith, P. (2006). Sex differences in cognitive abilities test scores: A UK national picture. British Journal of Educational Psychology, 76(3), 463-480.

doi: 10.1348/000709905x50906

Sylva, K. (1994). School influences on children's development. [Review]. J Child Psychol Psychiatry, 35(1), 135-170. doi: 10.1111/j.1469-7610.1994.tb01 135.x

Tarazi, R. A., Zabel, T. A., \& Mahone, E. M. (2008). Age-related differences in executive function among children with spina bifida/hydrocephalus based on parent behavior ratings. [Research Support, N.I.H., Extramural]. Clin Neuropsychol, 22(4), 585-602. doi: 10.1080/13854040701425940

UNICEF. (2014). Situational Analysis on the Rights of Children with Disabilities in Uganda. Kampala: UNICEF. 
USAID, \& AVSI. (2016). Sustainable Comprehensive REsponses (SCORE) for Vulnerable Children and their Families. Retrieved March 8, 2016

van't Veer, T., Meester, H., Poenaru, D., Kogei, A., Augenstein, K., \& Bransford, R. (2008). Quality of life for families with spina bifida in Kenya. Trop Doct, 38(3), 160-162. doi: $10.1258 / \mathrm{td} .2007 .070053$

Verpoorten, C., \& Buyse, G. M. (2008). The neurogenic bladder: medical treatment. [Review]. Pediatr Nephrol, 23(5), 717-725. doi: 10.1007/s00467-007-0691-z

Vinck, A., Nijhuis-van der Sanden, M. W. G., Roeleveld, N. J. A., Mullaart, R. A., Rotteveel, J. J., \& Maassen, B. A. M. (2010). Motor profile and cognitive functioning in children with spina bifida. European Journal of Paediatric Neurology, 14(1), 86-92. Doi: 10.1016/j.ejpn.2009.01.003

Warf, B. C., \& Campbell, J. W. (2008). Combined endoscopic third ventriculostomy and choroid plexus cauterization as primary treatment of hydrocephalus for infants with myelomeningocele: long-term results of a prospective intent-to-treat study in 115 East African infants. J Neurosurg Pediatr, 2(5), 310-316. doi: 10.3171/PED.2008.2.11.310

Warf, B. C., Ondoma, S., Kulkarni, A., Donnelly, R., Ampeire, M., Akona, J., ... Nsubuga, B. K. (2009). Neurocognitive outcome and ventricular volume in children with myelomeningocele treated for hydrocephalus in Uganda. J Neurosurg Pediatr, 4(6), 564-570. doi: 10.3171/2009.7.PEDS09136

Warf, B. C., Wright, E. J., \& Kulkarni, A. V. (2011). Factors affecting survival of infants with myelomeningocele in southeastern Uganda. J Neurosurg Pediatr, 7(2), 127-133. doi: 10.3171/2010.11.PEDS10428 
Femke Bannink resides in Uganda and is a $\mathrm{PhD}$ candidate at Ghent University. Prof. Dr. J.R.J. Fontaine and Prof. Dr. Geert van Hove are leading researchers at Ghent University, Faculty of Psychology and Educational Sciences, Ghent, Belgium.

Dr Richard Idro is a researcher and lecturer at Makerere University, College of Health Sciences, Department of Paediatrics and Child Health, Kampala, Uganda.

Contact Address: Femke Bannink, Ghent University, Faculty of Psychology and Educational Sciences, Department of Disability Studies and Inclusive Education, Henri Dunantlaan, 2, 9000 Ghent, Belgium. Email: femke.bannink@ugent.be 